\title{
How internal waves influence the vertical distribution of zooplankton
}

\author{
KARSTEN RINKE, ${ }^{,+}$INA HÜBNER,${ }^{*}$ THOMAS PETZOLDT, * SUSANNE ROLINSKI, * \\ MARIE KÖNIG-RINKE,* JOHANNES POST, ${ }^{\ddagger}$ ANDREAS LORKE ${ }^{\dagger}$ AND JÜRGEN BENNDORF* \\ *Institute of Hydrobiology, Dresden University of Technology, Dresden, Germany \\ ${ }^{\dagger}$ Limnological Institute, University of Konstanz, Konstanz, Germany \\ ${ }^{\ddagger}$ Hydromod Service GmbH, Hannover, Germany
}

\section{SUMMARY}

1. We present data with a high spatio-temporal resolution from a 72-h field survey in Bautzen Reservoir (Saxony, Germany). The aims of this survey were to observe hydrophysical processes during a period of unstable stratification in spring and investigate the effect of wind-induced internal waves on the vertical distribution of zooplankton. 2. Wind velocities up to $10 \mathrm{~m} \mathrm{~s}^{1}$ caused a strong downwelling event of warm water at the sampling site and led to the generation of internal waves with an amplitude of $4 \mathrm{~m}$. 3. The zooplankton community, which was dominated by Daphnia galeata, inhabited epilimnetic waters. Downwelling enlarged the thickness of the epilimnetic layer and, hence, led to high zooplankton abundances down to relatively deep water strata indicating lateral transport of zooplankton. As a consequence, area-specific zooplankton abundances increased considerably (max. fourfold) during downwelling.

4. We conclude that classical limnological field sampling, such as for monitoring purposes, can lead to severely biased estimates of zooplankton abundance due to the interfering effects of hydrophysical processes like internal waves.

5. Backscattering strengths measured by a simultaneously deployed Acoustic Doppler Current Profiler $(600 \mathrm{kHz})$ were found to be correlated with estimated zooplankton abundances based on plankton samples.

Keywords: Acoustic Doppler Current Profiler, Daphnia, hydrodynamics, internal waves, patchiness

\section{Introduction}

Distribution patterns of plankton are known to be patchy as a result of physical and biological processes (Pinel-Alloul et al., 1999; Pinel-Alloul, Methot \& Malinsky-Rushansky, 2004). Heterogeneous distributions of zooplankton originate from various processes, some of which can be attributed to internal factors; that is, they are related to the activity and swimming behaviour of the animals (Folt \& Burns,

Correspondence and present address: Karsten Rinke,

Limnological Institute, University of Konstanz,

Mainaustrasse 252, D 78464 Konstanz, Germany.

E mail: karsten.rinke@uni konstanz.de
1999). Other causes are linked to external factors, which force organisms to be transported passively, such as by wind-driven currents (George \& Edwards, 1976; George \& Winfield, 2000). Limnologists have properly documented a number of internal factors inducing spatial heterogeneity including swarming behaviour (Jakobsen \& Johnsen, 1987b; Pijanowska \& Kowalczewski, 1997), diel vertical and horizontal migrations (Stich \& Lampert, 1981; Kvam \& Kleiven, 1995), and the active orientation along horizontal and vertical gradients of temperature, food concentration and predation (e.g. Calaban \& Makarewicz, 1982; George, 1983; Kvam \& Kleiven, 1995; Jakobsen \& Johnsen, 1987a; Lampert, McCauley \& Manly, 2003). 
In contrast to this, we have a relatively poor understanding of external forcing of spatial heterogeneity. Some studies have highlighted the effect of wind-induced circulation on the horizontal distribution of plankton (George \& Edwards, 1976; George \& Winfield, 2000). Such wind-induced lateral transport processes were shown to account for $29-47 \%$ of basin scale spatial variance of zooplankton (Thackeray et al., 2004). However, wind-driven horizontal transport processes do also have an effect along the vertical axis, through up- or downwelling (George \& Edwards, 1976) or the induction of internal waves. Theoretical considerations showed that variations in vertical distribution of plankton as a consequence of internal waves can lead to biased estimates of plankton abundance (Gaedke \& Schimmele, 1991). It therefore appears important to test and quantify to what extent such variations in zooplankton vertical distribution really occur in a lake. Although George \& Edwards (1976) did not find any direct relationship between wind and vertical patchiness of zooplankton, other studies have indicated that the vertical distribution of zooplankton is affected by wind-induced internal waves (Megard et al., 1997; Easton \& Gophen, 2003). Similar interactions between internal waves and zooplankton distribution are known from marine environments (Trevorrow, 1998; McManus et al., 2005). However, a quantitative picture of the hydrodynamic mechanisms at work remained elusive in these investigations. The main objective of our study was, therefore, to investigate the interaction between internal waves and the vertical distribution of zooplankton in combination with a quantitative characterisation of the hydrophysical processes involved therein.

In addition to classical field sampling (e.g. plankton nets), studies on zooplankton distribution often apply other in situ techniques for zooplankton detection. Such techniques are either based on optical measurements (e.g. Davis et al., 1992; Sprules et al., 1992) or use hydroacoustics for zooplankton detection (e.g. Schröder \& Schröder, 1964; Smith et al., 1992). Hydroacoustic methods are advantageous because they are non-invasive and they deliver data almost instantaneously with a high spatial and temporal resolution (see Schulze, Williamson \& Sprules, 1992 and the publications cited therein). It has been successfully shown that lake zooplankton can be efficiently detected by hydroacoustics (Greenlaw, 1979; Gal,
Rudstam \& Greene, 1999) and their application in zooplankton distribution studies is well established (Megard et al., 1997; Hembre \& Megard, 2003). We therefore also applied hydroacoustic in situ detection of zooplankton according to the protocol given in Lorke et al. (2004).

This study is designed to measure vertical distribution patterns of zooplankton in combination with a thorough characterisation of the hydrophysical environment by conductivity, temperature and depth profiles (CTD) and by application of an Acoustic Doppler Current Profiler (ADCP). The ADCP measures backscattering signals of suspended particles ('scatterers') and calculates direction and velocity of the scatterers via the Doppler effect. Thus, it provides information about both the vertical distribution of backscattering intensity as a proxy for biological scatterers such as zooplankton and a vertical profile of current velocity and direction. Combining hydrophysical and limnological field techniques provides information to understand how wind-driven forces translate into hydrophysical processes, which finally interact with zooplankton spatial distribution.

\section{Methods}

Study site

This study was conducted in Bautzen Reservoir, an impoundment of the river Spree situated in eastern Saxony, Germany (Table 1, Fig. 1). In relation to its large surface area of more than 500 ha the reservoir displays a rather low maximum depth of about $13 \mathrm{~m}$. The Bautzen region is known to be windy and the surroundings of the reservoir do not provide any shelter against strong winds. Consequently, stratification in Bautzen Reservoir is weak and complete

Table 1 Main characteristics of Bautzen Reservoir

\begin{tabular}{lll}
\hline Characteristic & Unit & Value \\
\hline Location & & $51^{\circ} 13^{\prime} \mathrm{N}, 14^{\circ} 27^{\prime} \mathrm{E}$ \\
Trophic state & & Eutrophic \\
Catchment area & $\mathrm{km}^{2}$ & 310 \\
Altitude & $\mathrm{m}$ a.s.l. & 167.5 \\
Surface area & $\mathrm{ha}$ & 533 \\
Volume & $10^{6} \mathrm{~m}^{3}$ & 39.2 \\
Mean depth & $\mathrm{m}$ & 7.4 \\
Max. depth & $\mathrm{m}$ & 13.5 \\
Mean retention time & year & 0.45 \\
\hline
\end{tabular}




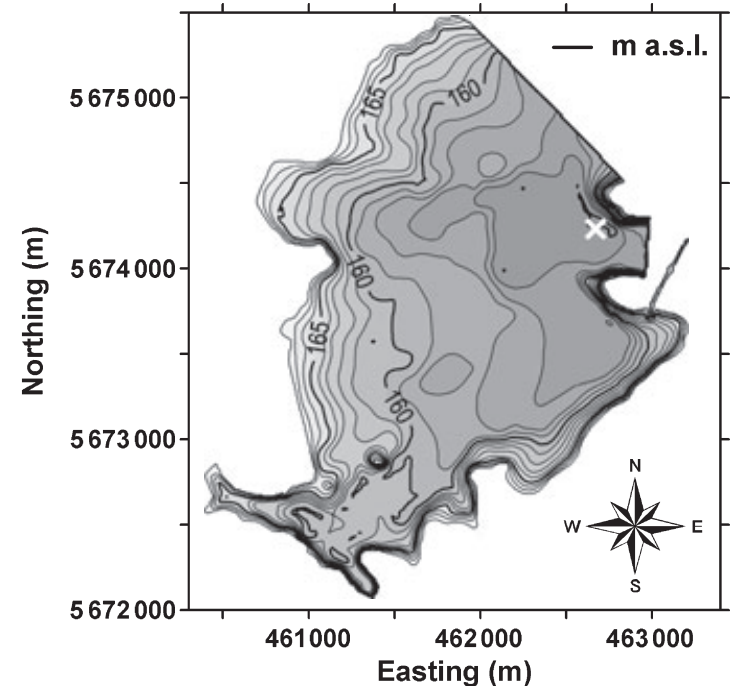

Fig. 1 Relief map of Bautzen Reservoir. Map coordinates are given as Universal Transverse Mercator coordinates (UTM; zone 33); the white cross denotes the sampling site; m.a.s.l., metres above sea level.

mixing during summer can be observed. Detailed information about the limnological aspects of this reservoir is given elsewhere (Benndorf et al., 2001; Hülsmann, 2003; Wagner et al., 2004). Sampling was conducted in the north-eastern part of the reservoir near the deepest point of the water body (Fig. 1). Water level at the sampling site, during our field survey, was approximately $10 \mathrm{~m}$.

\section{Field survey}

The field survey covered a period of $72 \mathrm{~h}$ starting from the evening of 5 May 2003. Vertical profiles of temperature, conductivity, $\mathrm{pH}$ and oxygen concentration were taken every 90 min using a multi-parameter probe (CTD60; Sea and Sun Technology, Trappenkamp, Germany). Simultaneous vertical profiles of chlorophyll $a$ were recorded with a multi-channel fluorescence probe (Flouroprobe, bbe Moldaenke, Kiel, Germany). The phytoplankton community at that time was dominated by diatoms, mainly Asterionella formosa (Hass.) and Fragilaria crotonensis (Kitton), and cryptophytes (Cryptomonas spp.).

Zooplankton samples were taken with a 5-L water sampler (Limnos.pl, Komorów, Poland), from five depths (one sample per depth; from 0, 3, 5, 8, $10 \mathrm{~m}$, respectively) four times per day at 01:00, 05:30, 13:00 and 20:30 hours (local time), which corresponds to midnight, sun rise, noon and sunset. Zooplankton was obtained by sieving through a $250-\mu \mathrm{m}$ mesh. The zooplankton community was dominated by Daphnia galeata (Sars), Eudiaptomus gracilis (Sars), and Cyclops vicinus (Uljanin). Although the daphnid species that dominated the community in abundance and biomass was morphologically identified as D. galeata, enzyme electrophoresis of individuals identified this species as a hybrid between D. galeata and D. hyalina (Daphnia galeata $\times$ hyalina, H. Voigt, personal communication). Samples were fixed in sugar formaldehyde according to Haney \& Hall (1973) and counted with a stereo microscope in the laboratory. Body lengths of individuals were measured using an image analysis system (SIS, Soft Imaging System GmbH, Münster, Germany) and used to calculate biomass (wet weight) using known length-weight relationships (von Tümpling \& Friedrich, 1999).

A $600 \mathrm{kHz}$ Acoustic Doppler Current Profiler (RDI Workhorse ADCP; RD Instruments, USA, http:// www.rdinstruments.com) was deployed on the bottom facing upward in the vicinity of the sampling site. ADCP measurements provided vertical profiles of current velocities at the sampling site and backscattering intensity as a proxy for zooplankton densities. The ADCP provides no information about taxonomic composition and size distribution of the organisms. A vertical current profile is recorded by the ADCP by means of the Doppler effect in the echo signals of scatterers, which are passively transported and drift with a distinct velocity relative to the ADCP. Hence, returning echo signals display a slightly changed frequency compared with the transmitted signal. The applied ADCP is equipped with four acoustic beams (transducer diameter: $73 \mathrm{~mm}$; beam width: $1.5^{\circ}$ ), which are tilted by $20^{\circ}$ to the vertical axis. Taking into account the prevailing low current velocities within the reservoir the averaging interval of the ADCP was set to $30 \mathrm{~min}$ and according to the applied ping rate of $0.33 \mathrm{~Hz}$ this resulted in 600 pings per value. A vertical resolution (depth cell size) of $0.5 \mathrm{~m}$ was used for data collection and analysis. The centre of the first depth cell was at a depth of $8.3 \mathrm{~m}$, or almost $2 \mathrm{~m}$ above the reservoir bottom. The uppermost two depth cells were omitted due to interfering effects of the water surface on the ADCP signals (air bubbles, wave action) resulting in 15 depth cells of usable data per time step. Backscattering intensities (counts) obtained from the ADCP were corrected for absorption by water and

(C): 
the spreading of the acoustic beam and finally converted to absolute volume backscattering strength (dB) according to Lorke et al. (2004). For the comparison of backscattering strength and zooplankton abundance we used the ADCP signal from that depth cell having the largest overlap with the vertical position of the water sampler. Throughout the study period we measured wind direction and velocity $10 \mathrm{~m}$ above the ground at an onshore meterological station (Thies Clima, Göttingen, Germany) approximately $250 \mathrm{~m}$ north-east of the sampling site.

For linear regression analysis between ADCP backscatter strength and abundance/biomass of total zooplankton/Daphnia a generalised linear model (GLM) with Gamma error distribution and identity link was applied in order to allow for heteroscedasticity. A likelihood ratio test between the fitted GLM and the respective null model was used to test for significance of fitted parameters. Coefficient of determination was calculated as percentage of deviance in the null-model explained by the GLM.

\section{Results}

Strong southerly winds with velocities exceeding $10 \mathrm{~m} \mathrm{~s}^{1}$ occurred during the morning of 6 May (4-9 h; Fig. 2). This wind event, having a relatively long fetch, induced a downwind transport of surface water and resulted in strong downwelling at the sampling site, which reached its maximum deflection at 9:00 hours (Fig. 3). At that time, cold hypolimnetic water was almost completely displaced by downwelling warmer waters. ADCP measurements revealed

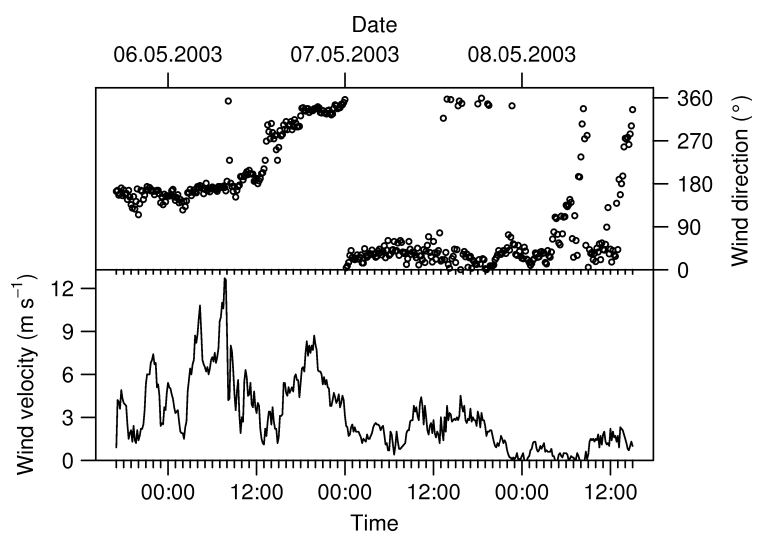

Fig. 2 Wind direction (upper panel) and wind velocity (lower panel) during the field survey (5 May to 8 May) measured at a height of $10 \mathrm{~m}$ on the shore of Bautzen Reservoir.

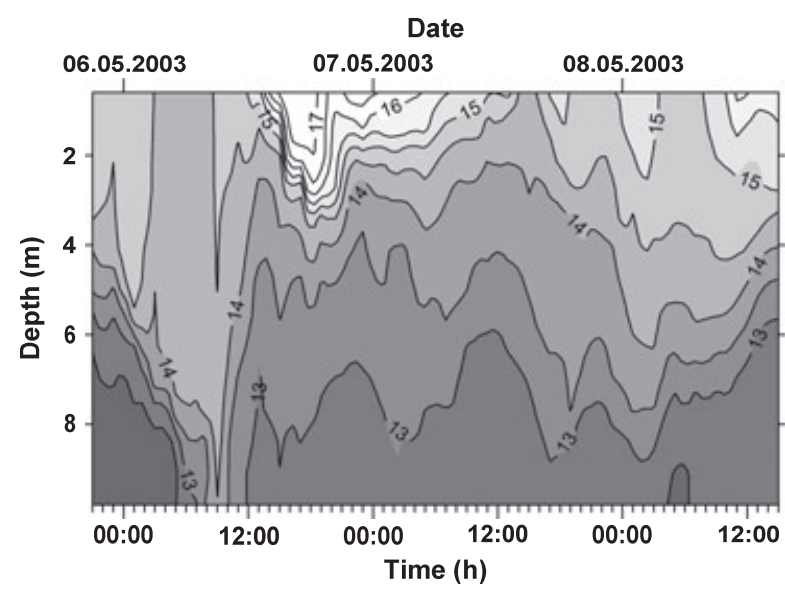

Fig. 3 Vertical temperature $\left({ }^{\circ} \mathrm{C}\right)$ profiles measured during the field survey (5 May to 8 May) in Bautzen Reservoir.

maximal horizontal currents of about $5-8 \mathrm{~cm} \mathrm{~s}^{1}$ and vertical currents of about $4-12 \mathrm{~mm} \mathrm{~s}^{1}$ (at depths between 2 and $8 \mathrm{~m}$ ). During the remainder of our survey, wind velocity was weaker and did not exceed $10 \mathrm{~m} \mathrm{~s}^{1}$ (Fig. 2). Thermal stratification of the water body, during the field survey, was characterised by an almost linear gradient of temperature with depth without a clearly defined thermocline. Isotherms showed large vertical fluctuations with maximum amplitudes exhibited by the $14{ }^{\circ} \mathrm{C}$ isotherm (Fig. 3). During the downwelling event, the $14{ }^{\circ} \mathrm{C}$ isotherm indicated a vertical displacement of this water layer of about $6 \mathrm{~m}$ over a period of $90 \mathrm{~min}$. Vertical current velocities (downward) during that time reached values between 4 and $12 \mathrm{~mm} \mathrm{~s}^{1}$. In the following days vertical oscillations of the isotherms still reached amplitudes of up to $3 \mathrm{~m}$, even during periods with relatively low wind velocities $\left(<3 \mathrm{~m} \mathrm{~s}^{1}\right)$. These oscillations, therefore, cannot be attributed to direct wind effects but rather represent propagating internal waves within the water body. Vertical current velocities during these weaker oscillations were lower and rarely exceeded $4 \mathrm{~mm} \mathrm{~s}^{1}$.

Vertical distribution of zooplankton during the field survey was characterised by high abundances in surface layers resulting in a positive correlation between zooplankton abundance and water temperature $\left(r^{2}=0.40, F=38.06\right.$, d.f. $\left.=58, P<0.001\right)$. Residuals of this linear model were unaffected by depth but showed a significant dependency on time since we observed higher zooplankton abundances on the first day than on the following days. However, a multiple linear model with temperature and time as 
Table 2 Results of a multiple linear regression model with temperature and time as independent variables and zooplank ton abundance as dependent variable

\begin{tabular}{lccc}
\hline & Estimate & $\mathrm{t}$ value & $P$ value \\
\hline Intercept & 571.1 & 3.16 & $<0.0001$ \\
Temperature & 54.6 & 6.81 & $<0.0001$ \\
Time & 33.8 & 3.11 & 0.003 \\
\hline
\end{tabular}

The interaction term was identified as not important by AIC. Overall statistics: $F$ statistic: 26.73 on 2 and 57 d.f., $r^{2} \quad 0.48$.

independent variables confirmed temperature to be the dominating factor (Table 2). Chlorophyll concentration showed no distinct vertical distribution pattern and varied between 7 and $10 \mu \mathrm{g} \mathrm{Chl} a \mathrm{~L}^{1}$. Zooplankton abundance was not correlated with chlorophyll concentration $\left(r^{2}=0.01, F=0.63\right.$, d.f. $=58, P=$ 0.43). No diurnal vertical migration of zooplankton was observed. However, the vertical distribution of zooplankton was strongly affected by downwelling and internal waves (compare Figs 3 \& 4). Individuals were passively transported and did not obviously compensate for vertical displacements created by these hydrophysical processes. During downwelling high zooplankton abundances from the near-surface layers were transported into deeper layers. At the same time zooplankton in the upper layers remained high, suggesting lateral transport of zooplankton towards the sampling site. As a consequence, downwelling increased areal abundance considerably (Fig. 5). Within the $72 \mathrm{~h}$ covered by the field survey areal abundance appeared to vary greatly, with maximal abundances being fourfold higher than minimal abundances. When the depth of the $14{ }^{\circ} \mathrm{C}$ isotherm is chosen as an indicator of downwelling, a

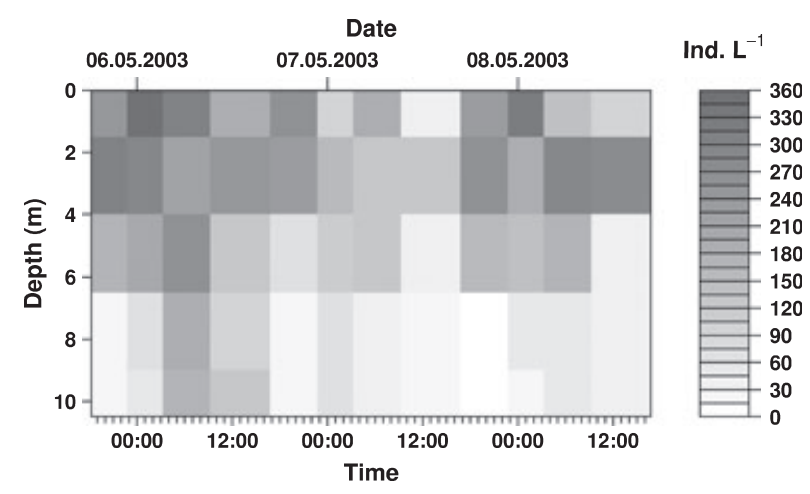

Fig. 4 Vertical distribution of zooplankton (total abundance of copepods and cladocerans) during the field survey (5 May to 8 May) in Bautzen Reservoir.

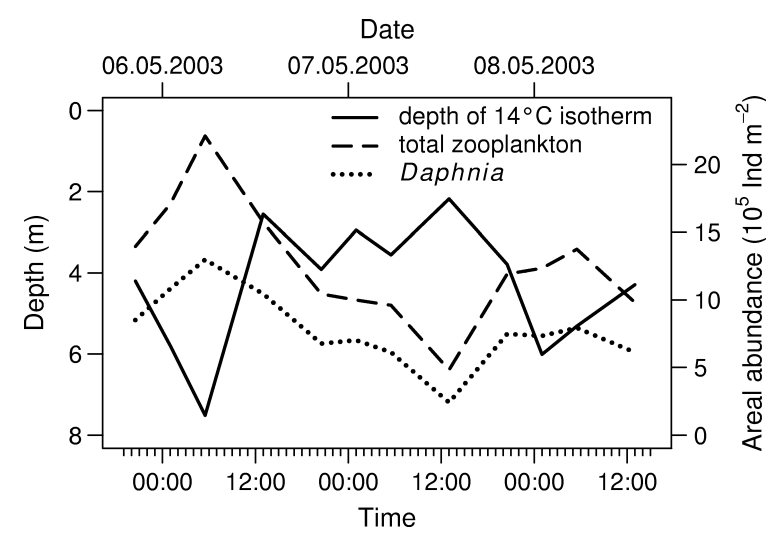

Fig. 5 Depth of the $14{ }^{\circ} \mathrm{C}$ isotherm and corresponding variation in the area specific abundance of total zooplankton and Daphnia.

positive correlation of this depth with areal zooplankton abundance and Daphnia abundance, respectively, emerged and accounted for $55 \%$ of total variance in areal abundance (Fig. 6).

Backscattering strength measured by the ADCP (Fig. 7) showed a pattern that corresponded to observed zooplankton distributions. Increased zooplankton abundances at greater depths during downwelling on the morning of 6 May were mirrored by stronger backscattering signals (compare Figs 4 \& 7). Furthermore, later fluctuations in vertical zooplankton distribution were mirrored by the spatio-temporal patterns in backscattering strengths (compare Figs 4 \& 7). Hence, total zooplankton abundance and Daphnia abundance, respectively, were significantly correlated with the measured backscattering strength (Fig. 8). Correlation coefficients of similar magnitude were found between backscattering strength and biomass

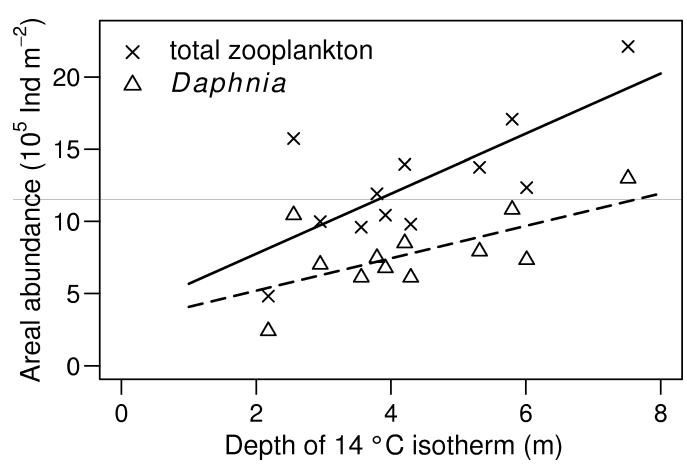

Fig. 6 Linear regression between depth of the $14{ }^{\circ} \mathrm{C}$ isotherm and corresponding area specific abundances of total zooplank ton (solid line; $y \quad 2.1 x+3.6, r^{2} \quad 0.55, F \quad 12.03$, d.f. 10 , $P \quad 0.006$ ) and Daphnia (dashed line; $y \quad 1.1 x+3.0, r^{2} \quad 0.42$, F $\quad 7.3$, d.f. $\quad 10, P \quad 0.02)$, respectively.

(C): 


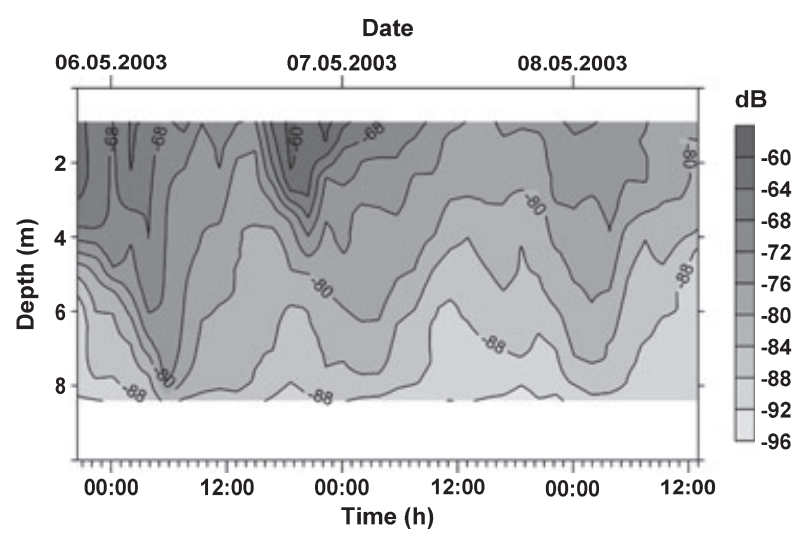

Fig. 7 Vertical profiles of acoustic backscattering strength (dB) during the field survey (5 May to 8 May) in Bautzen Reservoir. Backscatter data from the surface and bottom layer are not available due to Acoustic Doppler Current Profiler limitations (white areas; see Methods for explanation).

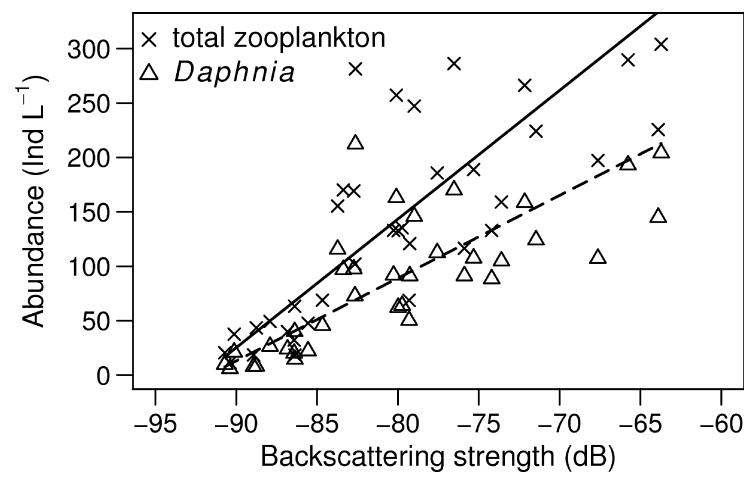

Fig. 8 Linear regressions of abundance of total zooplankton (solid line; $y \quad 11.82 x+1088.8, r^{2} \quad 0.68, F \quad 69.7$, d.f. 34 , $P<0.001$ ) and Daphnia (dashed line; $y \quad 7.6 x+697.3, r^{2} \quad 0.67$, $F \quad 58.41$, d.f. $\quad 34, P<0.001)$, respectively, as a function of Acoustic Doppler Current Profiler backscatter strength (gen eralised linear model with Gamma error distribution and iden tity link).

of Daphnia $\left(r^{2}=0.63, F=45.51\right.$, d.f. $\left.=34, P<0.001\right)$ and total zooplankton $\left(r^{2}=0.67, F=57.29\right.$, d.f. $=34$, $P<0.001)$.

\section{Discussion}

The results of our field survey reveal the highly dynamic character and variability of thermal stratification in wind-exposed lakes and reservoirs. By conducting high-resolution measurements of vertical temperature distribution over a period of $72 \mathrm{~h}$ we observed wind-driven internal waves with amplitudes of up to $6 \mathrm{~m}$. Such internal waves lead to considerable temporal variation in the thickness of the epi- and hypolimnion within a short period of time (hours). Areal estimates of zooplankton abundance, characterised by a heterogeneous vertical distribution, are subjected to large fluctuations due to these expanding and contracting water layers. By measuring the abundance of Daphnia, which inhabited the warmer epilimnion, we showed areal abundance to vary by a factor of 4 due to internal wave activity. We found that backscattering intensity measured by an ADCP is well correlated with the abundances of total zooplankton and Daphnia. Although designed to measure vertical velocity profiles in lakes and oceans, ADCPs also provide information on zooplankton distributions with a high spatial and temporal resolution (Fig. 7 and Lorke et al., 2004).

Our observations show that the distribution of zooplankton in Bautzen Reservoir is patchy. Repeated sampling of the zooplankton community revealed large fluctuations in total zooplankton and Daphnia abundance over a period of $72 \mathrm{~h}$ due to lateral transport. Variation in population size due to reproduction and mortality can be assumed to be of minor importance within this relatively short period. Instead, internal wave motions, involving fluctuation in the thickness of the epilimnic layer, accounted for $40 \%$ and $55 \%$ of the total variation in areal Daphnia and total zooplankton abundance, respectively.

We found the abundance of Daphnia and total zooplankton to be correlated with backscattering intensity with the latter explaining about $70 \%$ of the variability observed in zooplankton abundance. Nevertheless, unexplained variability accounts for about $30 \%$, which is still relatively high and could be due to a large number of sources, in part related to sampling techniques and in part for other reasons. Samplingrelated errors include errors associated with the net sampling and the differences in volume sampled by the two techniques. Backscattering intensity could potentially be biased by other scatterers besides zooplankton, such as large algal colonies or detritus flocks. However, we also assume that the different averaging time scale associated with the hydroacoustic and classical sampling is a major source of unexplained variability. Whereas the ADCP averaged the measured backscattering intensities over a period of $30 \mathrm{~min}$, the zooplankton samples were depthspecific samples collected within a few minutes.

Alternative techniques for in situ detection of zooplankton are provided by optical systems such as 
video recording or optical plankton counters (Baumgartner, 2003; Herman, Beanlands \& Phillips, 2004). These techniques can also provide information about the size and the shape of zooplankters and preliminary results show good agreement between traditional field sampling methods and plankton counter outputs. However, as this technique is based on shading of an optical signal, only narrow opening windows of a few centimetres can be applied and we do not know the extent to which escape reactions by zooplankters during lowering of the counter system affect the efficiency of detection. In contrast to this, acoustic techniques do not suffer from escape reactions and can sample larger volumes of water.

The need for calibration is common to all in situ electronic zooplankton sampling techniques (e.g. acoustic and optical devices). Such calibration requires sampling in close proximity (in time and space) to the area being sampled electronically and will always be necessary as it provides necessary information about the taxonomic composition of the population sampled, which cannot be derived from these in situ techniques. However, such acoustic and optical techniques can improve the temporal and spatial resolution of the measurements considerably, enabling the study of processes at finer scales.

Our results have implications for monitoring of lake zooplankton communities. Large fluctuations of zooplankton abundance can be triggered by internal waves or by wind-driven horizontal transport if the lake is exposed to strong winds. Sampling sites situated at a distance from the centre of the lake are especially susceptible to these hydrodynamically caused fluctuations. Such effects may become even stronger in large lakes where internal waves are affected by Coriolis force (Kelvin waves) and induce strong vertical displacements along the shore (Gaedke \& Schimmele, 1991). Monitoring programmes in lakes should therefore use information about the hydrophysical environment, such as from temperature profiles or thermistor chains, in order to account for possible effects of internal waves or wind-driven lateral transport processes on the distribution of plankton organisms.

\section{Acknowledgments}

We wish to thank Gideon Gal, two anonymous reviewers, and Colin Townsend for valuable

(): comments on former versions of the MS and for linguistic improvements. We are also grateful to Heike Kampe, Kathrin Jäschke, Anna Pretzschner, Dirk Goldmann and Lars Rudolf for their help in the field. Financial support was provided by the German Bundesministerium für Bildung und Forschung under grant 02 WT 0233 . KR was also partly supported by the Deutsche Forschungsgemeinschaft (DFG, grant RO 1008/11-1).

\section{References}

Baumgartner M.F. (2003) Comparison of Calanus finmarchicus fifth copepodite abundance estimates from nets and an optical plankton counter. Journal of Plankton Research, 25, 855868.

Benndorf J., Kranich J., Mehner T. \& Wagner A. (2001) Temperature impact on the midsummer decline of Daphnia galeata: an analysis of long-term data from the biomanipulated Bautzen Reservoir (Germany). Freshwater Biology, 46, 199212.

Calaban M.J. \& Makarewicz (1982) The effect of temperature and density on the amplitude of vertical migration of Daphnia magna. Limnology and Oceanography, 27, 262271.

Davis C.S., Gallager S.M., Berman M.S., Haury L.R. \& Strickler J.R. (1992) The Video Plankton Recorder (VPR): design and initial results. Archiv für Hydrobiologie Ergebnisse der Limnologie, 36, 6781.

Easton J. \& Gophen M. (2003) Diel variation in the vertical distribution of fish and plankton in Lake Kinneret: a 24-h study of ecological overlap. Hydrobiologia, 491, 91100.

Folt C.L. \& Burns C.W. (1999) Biological drivers of zooplankton patchiness. Trends in Ecology \& Evolution, 14, 300305 .

Gaedke U. \& Schimmele M. (1991) Internal seiches in Lake Constance influence on plankton abundance at a fixed sampling site. Journal of Plankton Research, 13, 743754 .

Gal G., Rudstam L.G. \& Greene C.H. (1999) Acoustic characterization of Mysis relicta. Limnology and Oceanography, 44, 371381.

George D.G. (1983) Interrelations between the vertical distribution of Daphnia and chlorophyll a in two large limnetic enclosures. Journal of Plankton Research, 5, 457475.

George D.G. \& Edwards R.W. (1976) The effect of wind on the distribution of chlorophyll a and crustacean plankton in a shallow eutrophic reservoir. Journal of Applied Ecology, 13, 667691. 
George D.G. \& Winfield I.J. (2000) Factors influencing the spatial distribution of zooplankton and fish in Loch Ness, UK. Freshwater Biology, 43, 557570.

Greenlaw C.F. (1979) Acoustical estimation of zooplankton populations. Limnology and Oceanography, 24, 226242.

Haney J.F. \& Hall D.J. (1973) Sugar-coated Daphnia: a preservation technique for Cladocera. Limnology and Oceanography, 18, 331333.

Hembre L.K. \& Megard R.O. (2003) Seasonal and diel patchiness of a Daphnia population: an acoustic analysis. Limnology and Oceanography, 48, 22212233.

Herman A.W., Beanlands B. \& Phillips E.F. (2004) The next generation of Optical Plankton Counter: the Laser-OPC. Journal of Plankton Research, 26, 1135 1145.

Hülsmann S. (2003) Recruitment patterns of Daphnia: a key for understanding midsummer declines? Hydrobiologia, 491, 3546.

Jakobsen P.J. \& Johnsen G.H. (1987a) Behavioural response of the water flea Daphnia pulex to a gradient in food concentration. Animal Behaviour, 35, 1891 1895.

Jakobsen P.J. \& Johnsen G.H. (1987b) The influence of predation on horizontal distribution of zooplankton species. Freshwater Biology, 17, 501507.

Kvam O.V. \& Kleiven O.T. (1995) Diel horizontal migration and swarm formation in Daphnia in response to Chaoborus. Hydrobiologia, 307, 177184.

Lampert W., McCauley E. \& Manly B.F.J. (2003) Trade-offs in the vertical distribution of zooplankton: ideal free distribution with costs? Proceedings of the Royal Society of London Series B-Biological Sciences, 270, 765773.

Lorke A., McGinnis D.F., Spaak P. \& Wuest A. (2004) Acoustic observations of zooplankton in lakes using a Doppler current profiler. Freshwater Biology, 49, 12801292.

McManus M.A., Cheriton O.M., Drake P.J., Holliday D.V., Storlazzi C.D., Donaghay P.L. \& Greenlaw C.F. (2005) Effects of physical processes on structure and transport of thin zooplankton layers in the coastal ocean. Marine Ecology-Progress Series, 301, 199215.

Megard R.O., Kuns M.M., Whiteside M.C. \& Downing J.A. (1997) Spatial distributions of zooplankton during coastal upwelling in western Lake Superior. Limnology and Oceanography, 42, 827840.

Pijanowska J. \& Kowalczewski A. (1997) Predators can induce swarming behaviour and locomotory responses in Daphnia. Freshwater Biology, 37, 649656.
Pinel-Alloul B., Methot G. \& Malinsky-Rushansky N.Z. (2004) A short-term study of vertical and horizontal distribution of zooplankton during thermal stratification in Lake Kinneret, Israel. Hydrobiologia, 526, 8598.

Pinel-Alloul B., Guay C., Angeli N., Legendre P., Dutilleul P., Balvay G., Gerdeaux D. \& Guillard J. (1999) Large-scale spatial heterogeneity of macrozooplankton in Lake of Geneva. Canadian Journal of Fisheries and Aquatic Sciences, 56, 14371451.

Schröder R. \& Schröder H. (1964) On the use of the echo sounder in lake investigations. Memorie dell'Instituto Italiano di Idrobiologia, 17, 167188.

Schulze P.C., Williamson C.E. \& Sprules W.G. (1992) Concluding remarks: a comparison of new devices for studying zooplankton in situ. Archiv für Hydrobiologie Ergebnisse der Limnologie, 36, 135140.

Smith S.L., Pieper R.E., Moore M.V., Rudstam L.G., Greene C.H., Zamon J.E., Flagg C.N. \& Williamson C.E. (1992) Acoustic techniques for the in situ observation of zooplankton. Archiv für Hydrobiologie Ergebnisse der Limnologie, 36, 2343.

Sprules W.G., Bergström B.I., Cyr H., Hargreaves B.R., Kilham S.S., MacIsaac H.J., Matsushita K., Stemberger R.S. \& Williams R. (1992) Non-video optical instruments for studying zooplankton distribution and abundance. Archiv für Hydrobiologie Ergebnisse der Limnologie, 36, 4558.

Stich H.B. \& Lampert W. (1981) Predator evasion as an explanation of diurnal vertical migration by zooplankton. Nature, 293, 396398.

Thackeray S.J., George D.G., Jones R.I. \& Winfield I.J. (2004) Quantitative analysis of the importance of wind-induced circulation for the spatial structuring of planktonic populations. Freshwater Biology, 49, 10911102.

Trevorrow M.V. (1998) Observations of internal solitary waves near the Oregon coast with an inverted echo sounder. Journal of Geophysical Research-Oceans, 103, 76717680.

von Tümpling W. \& Friedrich G. (1999) Biologische Gewässeruntersuchung. Urban \& Fischer, Jena.

Wagner A., Hülsmann S., Dörner H., Janssen M., Kahl U., Mehner T. \& Benndorf J. (2004) Initiation of the midsummer decline of Daphnia as related to predation, non-consumptive mortality and recruitment: a balance. Archiv für Hydrobiologie, 160, 123. 